\title{
Avaliação do Repertório de Habilidades Sociais de Adolescentes com Síndrome de Down
}

\author{
Assessment of the Social Skills Repertory of Adolescents with Down's Syndrome
}

\author{
Antonio Paulo Angélico ${ }^{*}, a$ \& Almir Del Prette ${ }^{b}$ \\ ${ }^{a}$ Universidade Federal de São João del-Rei, São João del-Rei, Brasil \\ \& ${ }^{b}$ Universidade Federal de São Carlos, São Carlos, Brasil
}

\begin{abstract}
Resumo
Objetivou-se investigar, a partir da metodologia observacional direta (filmagens), o repertório de habilidades sociais de um grupo de dez adolescentes com síndrome de Down. A classe de desempenhos pró-sociais predominou no repertório dos sujeitos em relação à classe de respostas de enfrentamento exibidas, não havendo, portanto, uma associação significativa entre estas duas classes de habilidades. Este fato pode ser explicado por se tratar de comportamentos distintos adquiridos em contingências específicas de aprendizagem e pelo número maior de categorias que compuseram a primeira classe. A maioria dos sujeitos apresentou déficit de respostas de enfrentamento, o que poderia ser indicativo da necessidade de intervenções preventivas e educacionais que contribuam para um melhor desempenho em situações com essas demandas. Palavras-chave: Habilidades sociais; Adolescentes; Síndrome de Down.
\end{abstract}

\begin{abstract}
Direct observational methodology (video recordings) was used to investigate the social abilities of a group of ten adolescents with Down's syndrome. Pro-social performance prevailed in the repertory of the individuals as compared to the coping responses presented. Therefore, there was no significant relation between those two classes of abilities. This result can be explained by the fact that those are different behaviors which are acquired in specific learning contingencies, and by the larger number of categories that composed the first class. Most of the subjects showed deficit in the coping responses, suggesting the need of educational and preventive interventions which contribute to improve the performance in situations with such demands.

Keywords: Social skills; Adolescents; Down's Syndrome.
\end{abstract}

A síndrome de Down é a aberração cromossômica que constitui uma das principais causas da deficiência mental de origem pré-natal. Resulta de um erro na distribuição cromossômica durante a divisão celular após a fertilização do óvulo pelo espermatozóide, que se pode apresentar de três formas: (a) trissomia 21 (3 cromossomos 21, ao invés dos 2 habituais): o indivíduo apresenta 47 cromossomos em todas as células, com um cromossomo extra. Representa uma maioria esmagadora, estando presente, conforme Schwartzman (1999), em cerca de 95\% dos casos. (b) mosaico: a pessoa apresenta uma mistura de células tanto normais quanto trissômicas. (c) translocação: há uma fusão de 2 cromossomos, na maioria das vezes o 21 e o 15 , resultando em um total de 46

\footnotetext{
"Endereço para correspondência: Universidade Federal de São João del-Rei, Depto de Psicologia, Praça Dom Helvécio, 74, Campus Dom Bosco, Bairro Fábricas, São João del-Rei, MG, Brasil, CEP 36301-160. E-mails: angelico@ufsj.edu.br e adprette@power.ufscar.br Pesquisa desenvolvida com apoio financeiro da Fundação de Amparo à Pesquisa do Estado de São Paulo (FAPESP, 02/06368-5)
}

cromossomos, apesar da presença de um cromossomo 21 extra aderido a um outro par.

As características fenotípicas mais comuns desta síndrome são: a braquicefalia, descrita por um diâmetro fronto-occipital muito pequeno, fissuras palpebrais com inclinação superior, pregas epicântais, base nasal achatada, pescoço curto, língua protusa e hipotonia muscular (Pereira-Silva \& Dessen, 2002).

Segundo Kaplan, Sadock e Grebb (1997), algumas evidências indicam que síndromes com base genética, dentre as quais, a síndrome de Down, estão associadas com manifestações comportamentais específicas. $\mathrm{Na}$ síndrome de Down, a função da linguagem é uma fraqueza relativa, enquanto a sociabilidade e aptidões sociais, tais como cooperação interpessoal e adequação a convenções sociais, são relativamente fortes. Neste sentido, várias fontes expressam que os indivíduos com síndrome de Down são dóceis, alegres, bem humorados e cooperativos, o que facilitaria o seu ajustamento ao lar (Glat \& Kadlec, 1984; Kaplan et al., 1997), além de sociáveis, amistosos e simpáticos (Dykens, Hodapp, \& Finucane, 2000). 
No entanto, um conjunto de dados científicos opõe-se às acepções anteriores que caracterizariam o perfil e o repertório de habilidades sociais ${ }^{1}$ dos indivíduos com síndrome de Down. A revisão empreendida por PereiraSilva e Dessen (2002) aponta que embora a maioria de crianças e adultos tenha se adequado ao estereótipo de afetivas e de temperamento fácil, há subgrupos de indivíduos com síndrome de Down que se apresentam agressivos, agitados e difíceis de manejar, o que demonstra que o temperamento desses indivíduos não é tão uniforme como se supunha. Em um outro estudo de PereiraSilva (2000), as crianças pré-escolares com síndrome de Down foram descritas como sendo birrentas, calmas ou agitadas e também irritadas. Além disso, desatenção, teimosia e desobediência são problemas de comportamento comuns em indivíduos com síndrome de Down (Cuskelly \& Dadds, 1992; Dykens, Shah, Sagun, Beck, \& King, 2002). Na adolescência, segundo Soresi e Nota (2000), indivíduos com síndrome de Down frequentemente experimentam dificuldades em estabelecer e manter relações com amigos na escola, bem como com figuras de autoridade.

Pode-se ressaltar ainda que nem sempre se observa uma preocupação dos estudos com uma definição operacional e funcional para as características de "docilidade" e "cooperação interpessoal" atribuídas aos portadores da síndrome (Dykens et al., 2000; Glat \& Kadlec, 1984; Kaplan et al., 1997). Pode ser que esses autores caracterizem o perfil social dos indivíduos com síndrome de Down como tal, comparando-os com indivíduos com outras síndromes, como o autismo, ou com distúrbio sensório-motor, que é o caso da paralisia cerebral. Todavia, esses estudiosos não fazem nenhuma menção a isso e, mesmo que o fizessem, continuaria a faltar-lhes uma definição operacional, objetiva e precisa desses termos, indicativos de virtudes e qualidades, usados para descrever fenômenos interacionais. Em contrapartida, Rosner, Hodapp, Fidler, Sagun e Dykens (2004), com base no Child Behavior Checklist (CBCL), observaram que sujeitos com síndrome de Down demonstraram os escores mais altos em competência social geral comparados com sujeitos com as síndromes de Prader-Willi e de Williams.

Por outro lado, considerando que habilidades sociais, conforme uma ampla literatura (A. Del Prette \& Del Prette, 2001; Z. A. P. Del Prette \& Del Prette, 1999; Gresham, 2009; Maag, 2006; Walker \& Severson, 2002), são de fato aprendidas, e tendo em vista os resultados do estudo de Cuskelly e Dadds (1992), Dykens et al. (2002), Perei-

\footnotetext{
${ }^{1}$ Habilidades sociais são definidas aqui como diferentes classes de comportamentos sociais existentes no repertório de um indivíduo para lidar de maneira adequada com as demandas das situações interpessoais. Demanda se refere à ocasião diante da qual se espera um determinado desempenho social em relação a uma ou mais pessoas (A. Del Prette \& Del Prette, 2001).
}

ra-Silva (2000) e da meta-análise realizada por Soresi e Nota (2000), é possível inferir que sociabilidade (facilitada por um temperamento dócil, alegre e bem-humorado) e aptidões sociais (expressas pela cooperação interpessoal e adequação a convenções sociais) não são características comportamentais próprias da síndrome de Down. Adicionalmente, poder-se-ia pensar que a suposta docilidade, afeição e cooperação interpessoal, geralmente atribuídas aos portadores da síndrome, conforme a referida literatura psiquiátrica e psicológica, poderiam ser consideradas como respostas de concordância e submissão às exigências e solicitações do meio, moldadas por contingências de aprendizagem específicas, sendo avaliadas como categorias de habilidades pró-sociais.

Dessa perspectiva teórica emerge uma questão importante: supondo que indivíduos com síndrome de Down apresentem uma tendência à sociabilidade e possuam um repertório de comportamentos pró-sociais bem elaborado, eles teriam igualmente respostas de enfrentamento para estabelecer interações de maior equilíbrio no cotidiano?

Entre os vários autores que trabalham com a temática do comportamento pró-social (Branco, 1983; Bryant \& Crockenberg, 1980; Eisenberg, Cameron, Tryon, \& Dodez, 1981; Krebs, 1983; Radke-Yarrow, Zahn-Waxler, \& Chapman, 1983; Rushton, 1982), aceita-se como prósocial qualquer comportamento que não seja agressivo ou destrutivo (antissocial), e que envolva a interação de dois ou mais indivíduos, promovendo o contato interpessoal (Z. A. P. Del Prette \& Del Prette, 2005).

No presente estudo, comportamento pró-social será definido como todo comportamento de contato social que favoreça e promova a manutenção imediata, ou a curto e médio prazo, de episódios interativos entre dois ou mais indivíduos, e que não seja caracteristicamente passivo na expressão de objetivos, direitos e sentimentos, ou agressivo, que atinge os objetivos pretendidos desrespeitando os direitos dos demais. Conforme A. Del Prette e Del Prette (2003) e Z. A. P. Del Prette e Del Prette (2003), o estilo comportamental agressivo (maior frequência de respostas agressivas) pode ser eficaz em muitas situações, porém, ao desconsiderar a necessidade do outro, gera mais temor que admiração. O estilo comportamental passivo se caracteriza por expressões hesitantes, dúbias e mesmo de evitações a situações que exigem confronto de opiniões. Z. A. P. Del Prette e Del Prette (2003) propõem que esses estilos podem ser imaginados em termos de um contínuo com posições opostas. O deslocamento para um lado significa maior passividade e, para o outro, maior agressividade. No centro, localizar-se-ia o estilo assertivo com maior prevalência de respostas de enfrentamento, de opinar, discordar, defender os próprios direitos e respeitar os direitos dos demais.

Já as respostas assertivas de enfrentamento, com base em Lange e Jakubowski (1976), seriam aquelas que visam à autoafirmação do indivíduo perante outros, à ga- 
rantia dos seus direitos e à expressão apropriada, direta $\mathrm{e}$ honesta dos seus pensamentos, sentimentos e crenças, que não violem o direito dos demais. Portanto, tais respostas podem ser definidas como a capacidade de o indivíduo se posicionar de forma adequada às demandas específicas do ambiente, ou seja, entre a inibição (passividade) e a agressividade. Mais especificamente, o comportamento assertivo permite esse posicionamento adequado se opondo à passividade e à agressividade.

Cabe mencionar que, usando os indexadores Scielo e Lilacs, a literatura científica brasileira não registrou nenhuma publicação de pesquisa que tenha como foco a temática das habilidades sociais envolvendo indivíduos com síndrome de Down. Sendo assim, verificou-se uma carência de estudos e pesquisas nessa área voltada para essa população específica. Além disso, com base em uma busca sistemática na literatura internacional, compreendendo o período de 2000 e 2009, usando os indexadores ISI Web of Knowledge, Medline e PsycInfo, por meio do cruzamento das palavras "Down's syndrome", "social skills", "adolescents", "teenage", "assertiveness", "pro-social skills" e "communication skills", também não se registraram estudos empíricos ou de revisão de literatura na área.

Para responder a pergunta de pesquisa, colocada acima, questionando se indivíduos com síndrome de Down apresentariam respostas de enfrentamento para dar equilíbrio a sua suposta sociabilidade e repertório bemelaborado de comportamentos pró-sociais, este estudo objetivou: (a) descrever o repertório geral de habilidades sociais de um grupo de adolescentes portadores da síndrome de Down, descrevendo e categorizando diversas habilidades sociais consideradas pró-sociais e de enfrentamento apresentadas por esses indivíduos; e (b) analisar as habilidades sociais tendo como base as classes de categorias analíticas pró-ativas e reativas.

\section{Método}

\section{Sujeitos}

Esta pesquisa foi realizada com a participação de dez adolescentes com síndrome de Down, na faixa etária de 12 a 17 anos, com o intuito de tornar mais homogêneas as características de desenvolvimento dos integrantes. O Termo de Consentimento Livre e Esclarecido (TCLE) foi obtido junto à direção da instituição de ensino na qual os sujeitos se encontravam regularmente matriculados e aos pais dos mesmos, depois de serem apresentados os principais objetivos e procedimentos do estudo (Processo - CEP - 082/2002 - Universidade Federal de São Carlos [UFSCar]). A seguir, a Tabela 1 com a caracterização dos sujeitos em termos de sexo, idade, nível socioeconômico da família, grau de escolaridade e instituição que frequentavam.

Tabela 1

Caracterização dos Sujeitos Participantes do Estudo

\begin{tabular}{lccccc}
\hline Sujeitos* $^{*}$ & Sexo & Idade & NSE da Família & \multicolumn{1}{c}{ Escolaridade } & Instituição \\
\hline Larissa & Feminino & 12 anos & Classe D & E.F. (currículo adaptado) & A \\
Júlia & Feminino & 15 anos & Classe A2 & E.F. (currículo adaptado) & A \\
Eduardo & Masculino & 15 anos & Classe A2 & $8^{\text {a }}$ série do Ensino Fundamental & B / A \\
Rogério & Masculino & 14 anos & Classe C & E.F. (currículo adaptado) & C \\
Leandra & Feminino & 15 anos & Classe B1 & E.F. (currículo adaptado) & C \\
Bernardo & Masculino & 14 anos & Classe C & E.F. (currículo adaptado) & C \\
Patrícia & Feminino & 15 anos & Classe D & E.F. (currículo adaptado) & C \\
Luan & Masculino & 17 anos & Classe C & E.F. (currículo adaptado) & C \\
Gustavo & Masculino & 16 anos & Classe C & E.F. (currículo adaptado) & C \\
Bruno & Masculino & 13 anos & Classe B2 & E.F. (currículo adaptado) & C
\end{tabular}

Nota. * Os nomes dos sujeitos são fictícios. As instituições A e B são particulares e a C, filantrópica. NSE: Nível Socioeconômico; E.F.: Ensino Fundamental.

Eduardo foi o único sujeito que se encontrava incluído no sistema regular de ensino, matriculado em uma instituição de Ensino Fundamental (B), apresentando o maior grau de escolaridade entre todos. Os demais sujeitos frequentavam instituições de atendimento a alunos com necessidades especiais (A e C), com currículo adaptado aos seus déficits e limitações de aprendizagem, não ha- vendo uma correspondência precisa entre o possível grau de escolaridade dos alunos com os níveis próprios do ensino fundamental.

Para efeito de uma melhor caracterização da amostra estudada, também foi obtida uma classificação socioeconômica das famílias dos sujeitos por meio do "Critério Brasil" (extraído de www.ibope.com.br). 


\section{Equipamentos e Instrumentos}

Foram utilizados os seguintes equipamentos e recursos: filmadora digital Sony Handycam Vídeo 8 / modelo CCD-TR403BR, fitas Sony MP120 8mm, fitas VHS Sony T-120, televisão, vídeocassete e protocolo de registro das filmagens realizadas.

\section{Procedimentos de Coleta de Dados}

Para o levantamento das habilidades sociais constantes no repertório de interação social dos sujeitos, foram efetuadas sete sessões de filmagens para cada um deles em diversas situações naturais e duas, em situações estruturadas, todas denominadas de contextos. As observações diretas em situações naturais consistiram das seguintes filmagens: (a) durante as atividades didáticas em sala de aula; (b) almoço ou lanche, dependendo da instituição em questão; (c) intervalo; (d) aula de educação física; (e) dança; e (f) brinquedoteca. As duas situações estruturadas foram: (a) reação à retirada provisória do almoço ou lanche do sujeito; e (b) respostas ao não ser contemplado na distribuição de doces para todos os alunos. Independentemente da reação apresentada pelos sujeitos, o alimento ou doce era entregue a eles após o transcorrer de alguns minutos. Essas situações propiciaram demandas para a ocorrência de prováveis desempenhos sociais específicos, visando a caracterizar o repertório de habilidades sociais dos sujeitos em assertivo, passivo ou agressivo.

A primeira sessão de filmagem realizada em sala de aula, objetivando à familiarização e adaptação dos alunos e professoras aos procedimentos e à presença do pesquisador na sala de aula, foi repetida no final do processo da coleta de dados em situações naturais. Os dados coletados em ambas as filmagens foram aproveitados para análise. Em geral, as sessões de filmagens tiveram uma duração de aproximadamente quinze minutos. O tempo médio de filmagem das sessões foi definido em consenso com outro pesquisador.

\section{Procedimentos de Análise dos Dados}

Inicialmente, diversas habilidades (ou categorias de registro), componentes de classes mais amplas, foram definidas tendo como base as seguintes fontes de referência: A. Del Prette e Del Prette (2001), Z. A. P. Del Prette e Del Prette (1999), Hildebrand (2000) e Martini (2003).

Para os fins almejados, o termo "comportamentos pró-sociais" abrangerá as seguintes classes das habilidades sociais: (a) comunicativas (aquelas que medeiam o contato entre as pessoas em um sistema de transmissão e recepção de mensagens); (b) de civilidade (desempenhos razoavelmente padronizados pelas normas e cultura de um grupo para determinadas situações sociais); (c) empáticas (respostas que expressam a compreensão das necessidades e desejos do outro); e (d) de expressão de sentimento positivo (ações que expressam aceitação e afeto pelo outro). Essas mesmas habilidades e as de enfrentamento foram também denominadas de respostas pró-ativas (que agem sobre o ambiente) e reativas (que respondem a ele). Estamos considerando a resposta ao ambiente como pró-ativa quando, em uma interação, a iniciativa de desempenho pertence ao sujeito em análise; e como reativa, quando ele reage a um comportamento iniciado por outro indivíduo.

A partir das filmagens de cada sujeito, foram transcritas as falas e registrados tanto os comportamentos nãoverbais quanto a direção do comportamento observado, de forma a obter uma caracterização do seu repertório de habilidades sociais. Concomitantemente à transcrição dos comportamentos, eram inferidas as habilidades correspondentes e computada a frequência de cada uma usando o protocolo de registro das filmagens realizadas.

Utilizando essas transcrições, procurou-se definir cada categoria componente das classes de habilidades sociais geradas anteriormente. Após esse trabalho, o conjunto de categorias produzidas foi submetido a outro pesquisador, reformulando, quando necessário, as definições propostas para garantir maior precisão e clareza das mesmas; e renomeando as categorias e/ou agrupando as sobrepostas, em alguns casos. Disso, resultou o sistema de classificação de categorias para a análise dos dados coletados, que foi continuamente revisado, sendo excluídas algumas categorias e produzidas outras que melhor se adequassem ao conteúdo das observações realizadas.

As habilidades sociais propostas para a análise dos desempenhos dos sujeitos em diferentes contextos de interação social e seus agrupamentos em classes mais amplas são apresentados na Tabela 2. As definições de algumas habilidades mais difíceis de serem inferidas serão oferecidas como legenda da referida tabela.

Para verificar a confiabilidade das observações realizadas, comparou-se o primeiro registro por um outro, após o intervalo de seis meses. Os índices de confiabilidade entre os dois registros foram obtidos pelo confronto de protocolos que corresponderam a um total de vinte por cento das filmagens efetuadas. Esses índices foram calculados, a partir da seguinte fórmula:

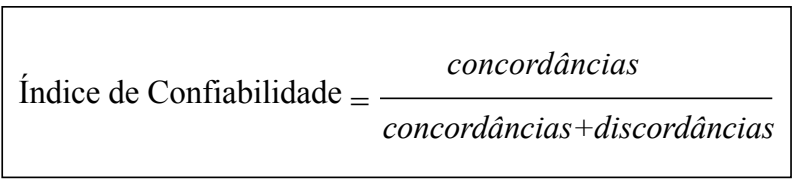

Os resultados dos testes de confiabilidade demonstraram um índice geral de 0,88 para todos os contextos, indicando como confiáveis os registros realizados e que as categorias empregadas foram bem definidas de modo que os desempenhos foram identificados sem muita dificuldade.

Para a análise estatística dos dados obtidos pelas filmagens, foram utilizados os Testes de Correlação de Spearman e o Multiple Analysis of Variance (MANOVA) 
Angélico, A. P. \& Del Prette, A. (2011). Avaliação do Repertório de Habilidades Sociais de Adolescentes com Síndrome de Down.

Tabela 2

Composição das Classes de Habilidades Sociais Propostas para a Análise dos Desempenhos Exibidos pelos Sujeitos

Classes de Habilidades Sociais (HS)

A. HS de Comunicação

A.1. Aproximar-se de outras pessoas

A.2. Iniciar contato e conversação

A.3. Estabelecer contato visual

A.4. Fazer perguntas

A.5. Responder perguntas

A.6. Autorrevelar-se ${ }^{(a)}$

A.7. Concordar (ação verbal)

A.8. Concordar (ação não-verbal) ${ }^{(\mathrm{b})}$

A.9. Gesto de expressar "não!"(c)

A.10. Imitar modelo

A.11. Seguir dica

A.12. Fazer comentário

A.13. Gratificar e elogiar

A.14. Solicitar avaliação

A.15. Avaliar

A.16. Acatar ordens

A.17. Seguir instruções

A.18. Solicitar oportunidade para falar

A.19. Gesto de "positivo"(d)

A.20. Encerrar conversação

B. HS de Civilidade

B.1. Cumprimentar

B.2. Agradecer

B.3. Prestar atenção

B.4. Despedir-se
C. HS Assertivas de Enfrentamento

C.1. Manifestar opinião

C.2. Fazer pedidos

C.3. Recusar pedidos

C.4. Dar ordens

C.5. Admitir falhas

C.6. Expressar desagrado

C.7. Chamar a atenção

C.8. Fazer crítica

C.9. Pedir mudança de comportamento

C.10. Defender-se de acusações

C.11. Fazer referência a si mesmo ${ }^{(\mathrm{e})}$

D. HS Empáticas

D.1. Expressar ajuda

D.2. Atender pedidos

E. HS de Expressão de Sentimento Positivo

E.1. Sorrir para o outro

E.2. Tocar o outro

E.3. Abraçar

E.4. Beijar o outro

E.5. Aceitar carinho

E.6. Fazer convite

F. Outras Categorias

F.1. Ignorar demandas ${ }^{(f)}$

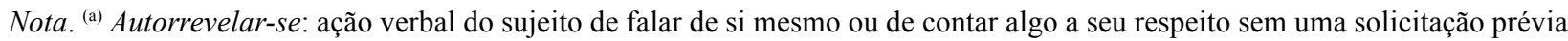
do interlocutor com o qual interage; (b) Concordar: ação não-verbal do sujeito de balançar a cabeça para cima e para baixo (movimentos verticais) com sentido afirmativo ou de se engajar em um comportamento sugerido pelo seu interlocutor; ${ }^{(c)}$ Gesto de expressar "não!'”: ação não verbal do sujeito de girar a cabeça para a direita e esquerda (movimentos horizontais) ou de exibir a mão fechada com o dedo indicador para cima movimentando-se para os lados, como forma de negação; (d) Gesto de "positivo": ação não verbal do sujeito de exibir a mão fechada com o dedo polegar para cima como sinal indicativo de que está tudo bem; ${ }^{(e)}$ Fazer referência a si mesmo: ação verbal do sujeito indicativa de autorreferência, e/ou não verbal de levar uma das mãos em direção ao próprio corpo para se referir à sua pessoa; ${ }^{(\mathrm{f})}$ Ignorar demandas: ação não verbal do sujeito de não responder diante de uma situação na qual se esperava um determinado desempenho social.

para medidas repetidas. Esses testes estatísticos foram aplicados sobre as médias aritméticas da frequência total de ocorrência de todas as classes de habilidades ou respostas investigadas (pró-sociais, assertivas de enfrentamento, pró-ativa e reativa).

\section{Resultados}

Todos os sujeitos demonstraram ter em comum no seu repertório as seguintes habilidades sociais: iniciar contato e conversação, estabelecer contato visual, fazer per- guntas, responder perguntas, concordar (ação verbal), acatar ordens, prestar atenção e sorrir para o outro.

Entre todos os sujeitos, Larissa foi a única que apresentou o gesto de despedir-se de outra pessoa $(n=1)$, não podendo ser desconsiderada a demanda gerada para a sua ocorrência. Em contrapartida, somente Júlia demonstrou a habilidade de encerrar conversação com outra pessoa $(n=1)$. Outro dado interessante é o fato de ela não ter ignorado nenhuma demanda proveniente do ambiente, embora tenha exibido desempenhos com baixíssimas frequências na sua interação com o meio. Apenas Larissa 
e Júlia exibiram a habilidade de se defender de acusações ( $n=1$ para ambas).

Eduardo demonstrou um número de habilidades bem distribuído entre as classes existentes. Rogério, Leandra e Bernardo apresentaram uma frequência relativamente baixa para todas as habilidades que exibiram durante as observações realizadas.

Leandra e Júlia foram as únicas que demonstraram a habilidade de agradecer a outra pessoa com quem interagiam ( $n=1$ para ambas). Luan foi o participante que apresentou um número maior de habilidades sociais de expressão de sentimento positivo em termos de frequência e diversidade. E, apenas Luan e Rogério emitiram o desempenho de beijar outra pessoa $(n=3$ para ambos).
Apenas Bruno exibiu o comportamento de admitir falhas $(n=2)$. Somente ele e Eduardo apresentaram a habilidade de avaliar o desempenho de alguém ou uma tarefa requerida a eles ( $n=6$ para ambos). Bruno e Luan apresentaram somente uma habilidade de civilidade: a de prestar atenção ( $n=13$ e 16, respectivamente).

Em termos de diversidade, Larissa, Eduardo e Bruno apresentaram, nas situações registradas, um número expressivo de habilidades assertivas de enfrentamento no seu repertório. Os sujeitos que mais ignoraram demandas geradas pelo ambiente para a emissão de habilidades sociais foram Rogério, Bernardo e Luan $(n=44,25$ e 33 respectivamente).

A Tabela 3 mostra as frequências de emissão das habilidades sociais, agrupadas em suas correspondentes classes, apresentadas para cada sujeito.

Tabela 3

Frequência de Ocorrência das Classes de Habilidades Sociais Exibida por Cada Sujeito do Estudo

\begin{tabular}{lccccc}
\hline \multicolumn{5}{c}{ Classes de Habilidades Sociais } \\
\cline { 2 - 6 } Sujeitos & Comunicação & Civilidade & $\begin{array}{c}\text { Assertivas de } \\
\text { Enfrentamento }\end{array}$ & Empáticas & $\begin{array}{c}\text { Expressão de } \\
\text { Sent. Positivo }\end{array}$ \\
\hline Larissa & 410 & 25 & 39 & 10 & 17 \\
Júlia & 241 & 4 & 17 & 1 & 13 \\
Eduardo & 248 & 29 & 79 & 6 & 12 \\
Rogério & 103 & 9 & 26 & 3 & 11 \\
Leandra & 86 & 16 & 14 & 3 & 4 \\
Bernardo & 156 & 11 & 26 & 1 & 20 \\
Patrícia & 195 & 10 & 39 & 8 & 26 \\
Luan & 197 & 8 & 13 & 2 & 44 \\
Gustavo & 343 & 13 & 66 & 2 & 26 \\
Bruno & 272 & & & & 28 \\
\hline
\end{tabular}

Nota. Sent. $=$ Sentimento.

Os sujeitos demonstraram frequências mais elevadas para a classe de habilidades sociais de comunicação, o que pode ser justificado pelas demandas geradas pelo ambiente para a sua ocorrência. Para as habilidades de comunicação, pode-se notar uma frequência similar de ocorrência para os sujeitos Júlia e Eduardo, Patrícia e Luan. Para as de civilidade, observou-se uma frequência similar de ocorrência, em ordem crescente, para Gustavo, Rogério, Patrícia e Bernardo; e uma semelhança de frequência para Leandra e Luan. Para as de enfrentamento, Eduardo e Bruno obtiveram as maiores frequências; evidenciando-se uma frequência similar de ocorrência para Luan, Leandra e Júlia; e uma semelhança de frequência para Rogério e Bernardo, Larissa e Patrícia. Para as empáticas, registrou-se uma semelhança de frequência entre Júlia e Bernardo, Luan e Bruno, Rogério e Leandra; e uma frequência similar, em ordem crescente, para esta mesma sequência de sujeitos, seguida de Gustavo, Eduardo, Patrícia e Larissa. Para as de expressão de sentimento positivo, a semelhança de frequência ocorreu para Patrícia e Gustavo, verificando-se uma frequência similar em ordem crescente para Rogério, Eduardo e Júlia.

Essas mesmas habilidades sociais também foram analisadas, a partir dos conceitos de respostas pró-ativas e reativas, como demonstrado pela Tabela 4. 
Tabela 4

Classificação das Habilidades Sociais em Respostas Pró-ativas e Reativas

Pró-ativas: aproximar-se de outras pessoas, iniciar contato e conversação, estabelecer contato visual, fazer perguntas, autorrevelar-se, fazer comentário, gratificar e elogiar, solicitar avaliação, avaliar, solicitar oportunidade para falar, gesto de "positivo", e encerrar conversação (habilidades sociais de comunicação); cumprimentar, e despedir-se (habilidades sociais de civilidade); manifestar opinião, fazer pedidos, dar ordens, chamar a atenção, fazer crítica, e fazer referência a si mesmo (habilidades sociais assertivas de enfrentamento); expressar ajuda (habilidade social empática); sorrir para o outro, tocar o outro, abraçar, beijar o outro, e fazer convite (habilidades sociais de expressão de sentimento positivo).

Reativas: responder perguntas, concordar (ação verbal), concordar (ação não-verbal), gesto de expressar "não!", imitar modelo, seguir dica, acatar ordens, e seguir instruções (habilidades sociais de comunicação); agradecer, e prestar atenção (habilidades sociais de civilidade); recusar pedidos, admitir falhas, expressar desagrado, pedir mudança de comportamento, e defender-se de acusações (habilidades sociais assertivas de enfrentamento); atender pedidos (habilidade social empática); aceitar carinho (habilidade social de expressão de sentimento positivo).

A habilidade de manifestar opinião foi considerada como pró-ativa por ser exibida pelo participante, a partir de uma afirmação, comentário ou ideia expressa pelo seu interlocutor que não constitui um antecedente social dirigido, necessariamente, para a sua ocorrência. A Figura 1 apresenta a percentagem de frequência das respostas pró-ativas e reativas exibida pelos sujeitos.

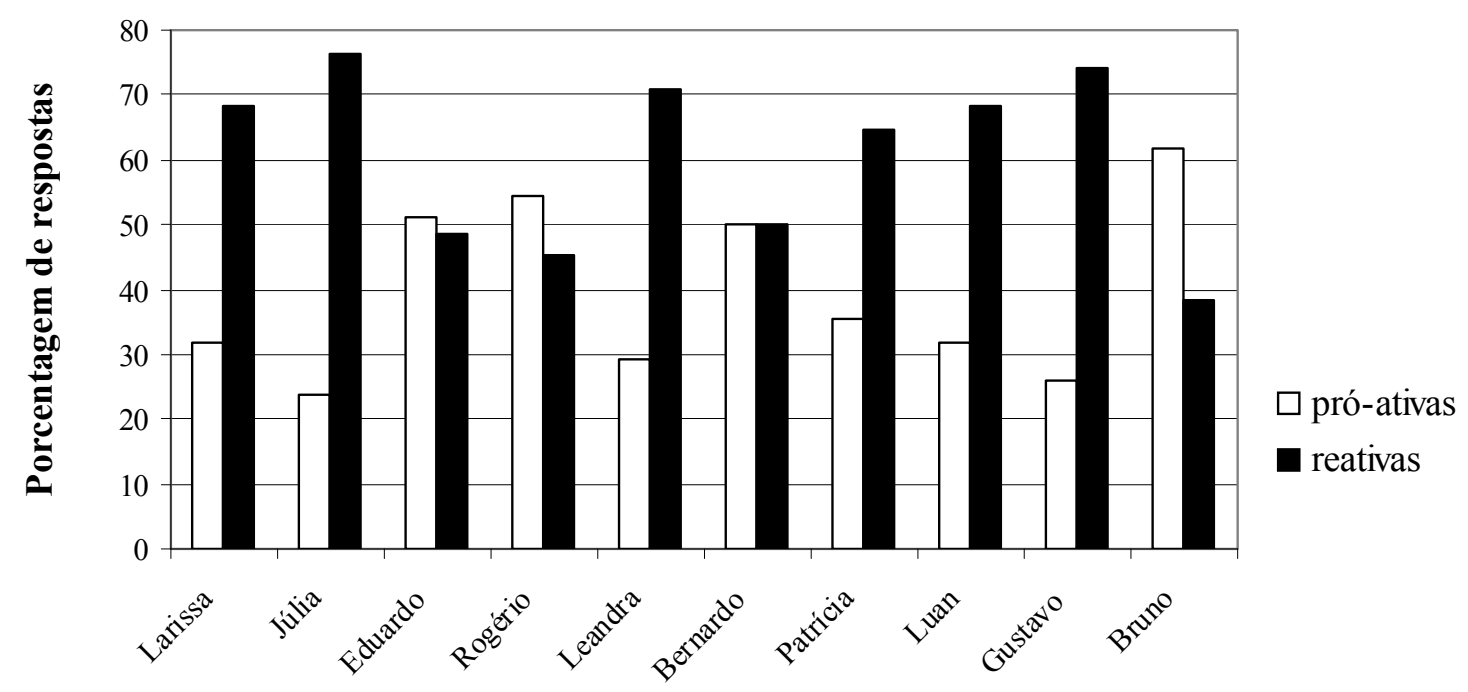

Sujeitos

Figura 1. Porcentagem da frequência de respostas pró-ativas e reativas no repertório dos sujeitos

Observou-se a predominância de respostas reativas no repertório da maioria dos sujeitos (Larissa, Júlia, Leandra, Patrícia, Luan e Gustavo), com exceção de quatro deles (Eduardo, Rogério, Bernardo e Bruno) que apresentaram uma percentagem maior de frequência de respostas próativas ao ambiente. Larissa e Luan obtiveram percentagens praticamente idênticas de respostas para as duas classes de respostas (31,7 e 31,6\% para a pró-ativa; 68,3 e
$68,4 \%$ para a reativa), ao passo que Júlia e Gustavo alcançaram porcentagens próximas $(23,6$ e $25,9 \% ; 76,4$ e $74,1 \%$, respectivamente).

Eduardo demonstrou um equilíbrio em termos de emissão de respostas pró-ativas $(51,3 \%)$ e reativas $(48,7 \%)$ ao ambiente, ao passo que Bernardo apresentou uma distribuição homogênea de frequência para essas duas classes de respostas. 
Utilizando o Teste de Correlação de Spearman, verificou-se uma relação forte e significativa $(\rho=0,67, p=$ $0,034)$ entre as respostas pró-ativas e de enfrentamento apresentadas pelos sujeitos, indicando que quanto mais frequente o uso do repertório de respostas pró-ativas pelos sujeitos, mais frequente será o uso de suas habilidades de enfrentamento. Também foi constatada uma relação muito forte $(\rho=0,83, p=0,003)$ entre as habilidades pró-sociais e as respostas reativas exibidas por eles, sugerindo que quanto maior a emissão de comportamentos de contatos sociais por um indivíduo, maior será a sua apresentação de respostas reativas a esses episódios interativos.

Para responder à questão central desta pesquisa, serão apresentados, na Figura 2, as frequências médias das habilidades pró-sociais e de enfrentamento registradas pelos sujeitos.

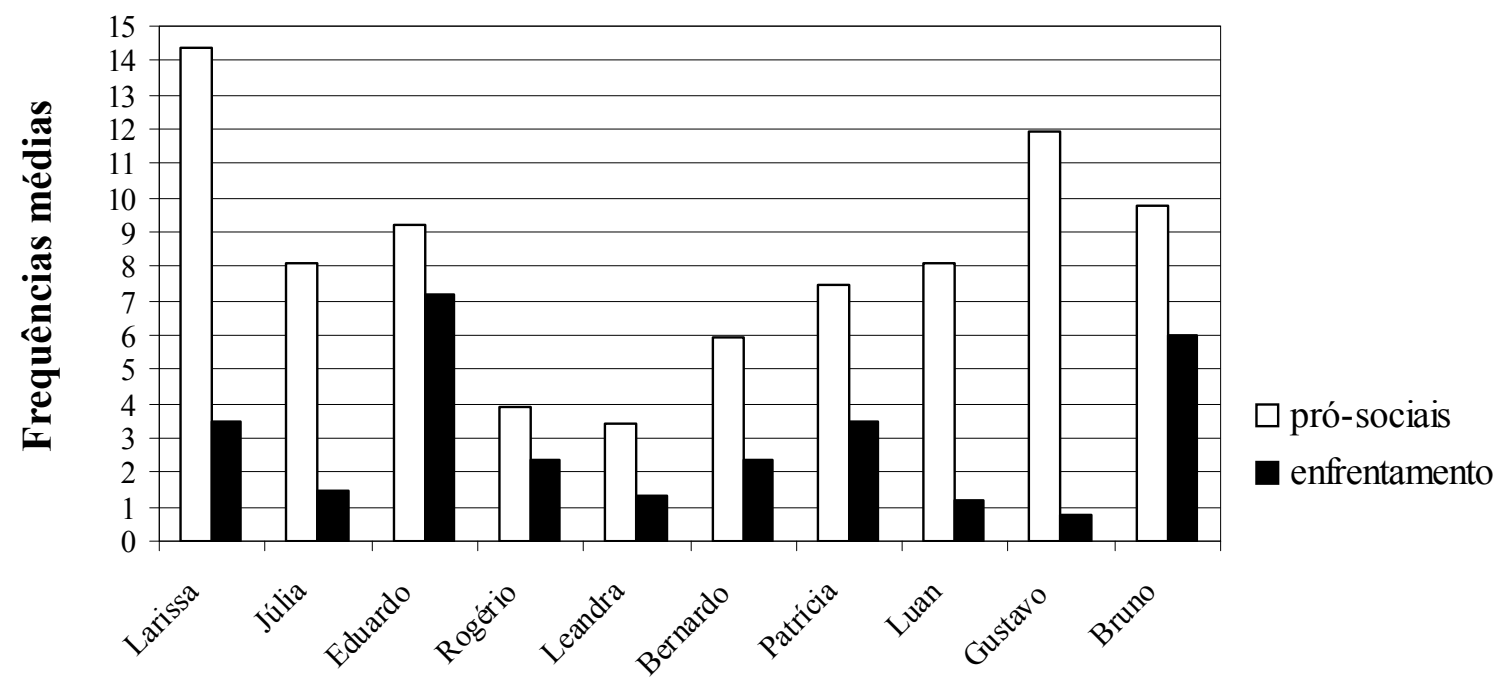

Sujeitos

Figura 2. Frequências médias das habilidades pró-sociais e de enfrentamento exibida pelos sujeitos

É evidente o contraste entre as classes de habilidades pró-sociais e de enfrentamento exibidas pelos sujeitos, com uma predominância de desempenhos constituintes da primeira classe. Eduardo, Rogério e Leandra demonstraram uma diferença de escores menos acentuada entre essas duas classes de comportamentos, quando comparados com os exibidos pelos demais sujeitos.

Considerando o repertório de desempenhos avaliados dos dez sujeitos, $88,9 \%$ constituem-se de habilidades pró-sociais $(n=2633)$ e $11,1 \%$ de respostas de enfrentamento $(n=328)$, sendo observada uma diferença acentuada existente entre as duas classes. Empregando o Teste de Correlação de Spearman para os dados obtidos, não foi encontrada uma relação significativa ( $\rho=0,21, p=0,564)$ entre o repertório de comportamentos pró-sociais e as respostas de enfrentamento demonstradas pelos sujeitos, apontando para a independência funcional entre estas duas classes de comportamentos em relação às demandas do ambiente.

O Teste MANOVA para medidas repetidas foi utilizado para examinar diferenças entre as médias dos sujeitos no que se refere às classes de habilidades investigadas. $\mathrm{O}$ resultado do teste revelou uma diferença significativa na frequência de uso das habilidades pró-sociais e de enfrentamento $\left(F_{(1,9)}=22,38, p<0,001\right)$ pelos sujeitos. Também se evidenciou diferença significativa para as classes de habilidades sociais de comunicação, de civilidade, assertivas de enfrentamento, empáticas e de expressão de sentimento positivo $\left(F_{(4,9)}=22,20, p<0,001\right)$ entre eles. Essas análises mostram, portanto, haver diferença extremamente significativa na frequência de uso das diferentes classes de habilidades sociais pelos sujeitos.

Os desempenhos de enfrentamento dos sujeitos observados nas situações estruturadas serão tomados agora como foco de análise. Apenas dois sujeitos (Larissa e Eduardo) apresentaram desempenhos de enfrentamento para as duas situações, pedindo o comestível para a professora ou diretora (discordando das situações geradas e defendendo seus próprios direitos); seis deles (Júlia, Rogério, Leandra, Bernardo, Luan e Gustavo) demonstraram respostas passivas para ambas (apresentando concordância às situações, e não defendendo seus direitos); 
e dois (Bruno e Patrícia, respectivamente) permutaram entre o responder assertivo e passivo, variabilidade esta que pode ser explicada pela efetividade do reforço para o desempenho de cada um deles.

\section{Discussão e Conclusões}

A necessidade de explicar o comportamento das pessoas é tão forte que muitos são levados a antecipar a investigação científica construindo teorias de causação interna altamente improváveis (Skinner, 1953/2003). Ao se assumir a perspectiva de que indivíduos com síndrome de Down nascem dóceis e cooperativos, conforme pode ser inferido da literatura psicológica e psiquiátrica consultada (Dykens et al., 2000; Glat \& Kadlec, 1984; Kaplan et al., 1997), ver-se-á que essa afirmação não vem sendo confirmada em vários estudos (Cuskelly \& Dadds, 1992; Dykens et al., 2002; Pereira-Silva, 2000; Pereira-Silva \& Dessen, 2002; Soresi \& Nota, 2000). Assumir os genes como causa para explicar o comportamento é sempre o caminho mais tortuoso (Skinner, 1989/2002), considerando que um indivíduo isolado em um ambiente não-social será incapaz de adquirir um repertório de comportamento que permita classificá-lo como dócil e cooperativo.

Como defendido por Skinner (1953/2003), mesmo quando pode ser demonstrado que certo aspecto do comportamento de um indivíduo é devido a sua constituição genética, o possível uso dessa explicação é relativamente limitada e, ao mesmo tempo, pode funcionar impeditivamente em relação às tentativas educacionais. Se esse indivíduo possui certas limitações inerentes a sua constituição genética, apenas poder-se-á usar mais inteligentemente as técnicas de ensino em resposta a elas, ao passo que não se pode alterar o fator.

Um possível equívoco da literatura sobre a sociabilidade de indivíduos com síndrome de Down é, frequentemente, descrever o comportamento não como verbos que especificam ação, mas como adjetivos ou traços que apenas descrevem características ou aspectos de ação. Skinner (1953/2003) considera tais tipos de termos anticientíficos e enfatiza a necessidade de procurar pelos determinantes relacionados funcionalmente às formas essenciais do comportamento. Em extensão às ponderações de Skinner (1989/2002), as pessoas também não se comportam dócil ou cooperativamente porque são dóceis ou cooperativas, e as condições sob as quais são dóceis ou cooperativas são as condições sob as quais se comportam dócil ou cooperativamente.

Nesse sentido, o perfil de um indivíduo como de uma pessoa dócil e cooperativa é atribuído pelo que ele faz em resposta ao seu ambiente mais imediato. E o que ele faz não pode ser simplesmente originado pela sua constituição genética, tomada, a priori, sem considerar sua história pessoal e o seu cenário de vida atual. O hábito de buscar dentro do indivíduo uma explicação para o seu comportamento tende a obscurecer as variáveis que es- tão fora dele, em seu ambiente imediato e em sua história de aprendizagem. Mesmo que as pessoas possuam alguma propensão herdada geneticamente, serão os sistemas educacionais, principalmente a família e escola, e seus contextos associados de aprendizagem, que moldarão a sua maneira de se comportar.

Até certo ponto, pode-se dizer que as características de docilidade e cooperação interpessoal atribuídas às pessoas com síndrome de Down estejam atreladas ao predomínio de respostas reativas no repertório da maioria dos sujeitos participantes desta pesquisa, mas o que não permite, de modo algum, ignorar as variáveis externas que exercem controle sobre as diferentes classes de habilidades consideradas. Apenas nesse aspecto é que poderia existir alguma generalidade dos resultados obtidos neste estudo com a literatura da área em termos de se caracterizar repertório social dos indivíduos com síndrome de Down.

Todas essas considerações cumprem o papel de justificar a grande variabilidade do repertório de habilidades sociais encontrada entre os sujeitos desta pesquisa, com restrição às diferenças em demandas geradas pelo ambiente para a sua ocorrência. É preciso considerar também que as pessoas apresentam uma variedade de respostas sociais frente a diferentes situações e momentos, o que implica uma análise situacional do seu desempenho. Por exemplo, uma pessoa que demonstre comportamentos predominantemente assertivos no seu repertório pode apresentar, uma vez ou outra, desempenhos passivos ou agressivos (A. Del Prette \& Del Prette, 2001) em função da contingência presente em termos de ambiente físico (escola, casa, clube esportivo, rua ou igreja), indivíduo com quem interage (pai, mãe, irmão, professora, amigo, colega de classe ou estranho) e natureza da interação (brincadeira, competição, discordância de opinião, expressão de desagrado, conversa trivial, provocação ou participação em sala de aula), considerando-se também o histórico da relação envolvendo a díade ou grupo em que a interação ocorre.

Por meio do levantamento de linha de base realizado, não se constatou uma correlação significativa entre o repertório de habilidades pró-sociais dos sujeitos e seus comportamentos de enfrentamento, mas verificou-se a existência de uma relação forte entre as classes de respostas pró-ativas e de enfrentamento apresentadas por eles, indicando que quanto mais frequente o uso do repertório de respostas pró-ativas pelos indivíduos, mais frequente será o uso de suas habilidades de enfrentamento.

Poder-se-ia afirmar que o contraste de frequência entre as habilidades pró-sociais e as de enfrentamento seria justificado tanto pelo fato de a primeira classe possuir um número bem maior de categorias componentes quanto pelas demandas geradas para a sua ocorrência. No entanto, verificou-se, também, nas situações estruturadas investigadas, que a maioria dos sujeitos apresentou um déficit de respostas assertivas de enfrentamento em seu 
repertório comportamental, o que poderia ser indicativo, caso outras avaliações confirmassem, da necessidade de intervenções preventivas e educacionais que contribuam para um melhor desempenho em situações com essas demandas. Essas respostas dariam um maior equilíbrio ao repertório deles para lidarem de modo mais eficiente com seu ambiente. Ademais, a ausência de uma relação significativa entre o repertório de comportamentos prósociais e as respostas de enfrentamento demonstradas pelos sujeitos pode ser explicada por se tratar de classes de habilidades ou condutas distintas adquiridas em contingências específicas de aprendizagem.

Delimitando a linha de raciocínio apresentada por Castiñeiras (1998) para a amostra deste estudo, se as pessoas com síndrome de Down, com déficit de habilidades sociais, pudessem aprender desempenhos mais adequados diante de diferentes demandas, poderiam integrar-se mais facilmente em distintas áreas da comunidade, conseguindo uma aceitação pessoal maior entre as pessoas sem necessidades especiais. Contudo, essa aprendizagem requer, primeiramente, uma avaliação das habilidades sociais que integram o seu repertório e dos possíveis déficits apresentados em suas relações interpessoais. Nessa direção, Gresham (2000) argumenta que observações sistemáticas do comportamento representam um dos mais importantes métodos para avaliação de habilidades sociais. Segundo esse autor, os dados de observação são muito sensíveis a efeitos de intervenção e devem ser incluídos em toda avaliação de habilidades sociais e atividades de intervenção.

Em síntese, pode-se afirmar que este estudo contou com o emprego de observações sistemáticas, enquanto método de pesquisa, que seguramente poderá ampliar o conhecimento existente acerca do repertório de habilidades sociais de adolescentes com síndrome de Down, contribuindo, dessa forma, para oferecer subsídios ao desenvolvimento e implementação de futuros programas de Treinamento em Habilidades Sociais destinados à amostra de sujeitos utilizada. Estudos descritivos mais extensos com amostras mais amplas poderiam dar continuidade a essa caracterização, sendo de grande relevância para o planejamento de ensino dirigido a essa população.

Uma nova pergunta de pesquisa se coloca frente aos resultados obtidos neste estudo: a predominância de habilidades pró-sociais e respostas reativas ao ambiente no repertório dos sujeitos em oposição as suas condutas de enfrentamento e pró-ativas, respectivamente, também seria encontrada em indivíduos sem síndrome de Down? Para responder essa indagação, será necessário comparar os dados obtidos nesta pesquisa com os coletados com uma população de adolescentes que não apresentem necessidades educativas especiais.

Segundo Fishler e Koch (1991), a média de QI (quociente de inteligência), nos casos de síndrome de Down, na forma de mosaico, é significativamente maior do que em indivíduos com trissomia 21 simples, e muitas pessoas com mosaicismo demonstram melhores habilidades verbais e percepto-visuais em relação àquelas com trissomia. Haveria alguma relação entre o tipo de aberração cromossômica (trissomia 21, mosaico ou translocação), o nível de comprometimento da linguagem e possíveis déficits consequentes em habilidades sociais apresentados pelos indivíduos com síndrome de Down?

\section{Referências}

Branco, A. U. A. (1983). Comportamento pró-social: Análise conceitual e variáveis correlatas. Arquivos Brasileiros de Psicologia, 39(2), 153-169.

Bryant, B. K., \& Crockenberg, S. B. (1980). Correlates and dimensions of prosocial behavior: A study of female siblings with their mothers. Child Development, 51(2), 529-544.

Castiñeiras, J. R. A. (1998). La educación inclusiva y las habilidades sociales. In J. R. A. Castiñeiras, Atención a diversidade e habilidades sociais (pp. 331-351). A Coruña, España: Deputación Provincial.

Cuskelly, M., \& Dadds, M. (1992). Behavioural problems in children with Down's syndrome and their siblings. Journal of Child Psychology \& Psychiatry \& Allied Disciplines, 33(4), 749-761.

Del Prette, A., \& Del Prette, Z. A. P. (2001). Psicologia das relações interpessoais: Vivências para o trabalho em grupo. Petrópolis, RJ: Vozes.

Del Prette, A., \& Del Prette, Z. A. P. (2003). Treinamento assertivo ontem e hoje. In C. E. Costa, J. C. Luzia, \& H. H. N. Sant'Anna (Eds.), Primeiros passos em análise do comportamento e cognição (pp. 149-166). Santo André, SP: ESETec.

Del Prette, Z. A. P., \& Del Prette, A. (1999). Psicologia das habilidades sociais: Terapia e educação. Petrópolis, RJ: Vozes.

Del Prette, Z. A. P., \& Del Prette, A. (2003). Assertividade e religiosidade, muito além de uma rima. In F. C. S. Conde \& M. Z. S. Brandão (Eds.), Falo ou não falo: Expressando sentimentos e comunicando idéias (pp. 141-157). Arapongas, PR: Mecenas.

Del Prette, Z. A. P., \& Del Prette, A. (2005). Psicologia das habilidades sociais na infância: Teoria e prática. Petrópolis, RJ: Vozes.

Dykens, E. M., Hodapp, R. M., \& Finucane, B. M. (2000). Genetics and mental retardation syndromes: A new look at behavior and interventions. Baltimore: Paul $\mathrm{H}$. Brookes.

Dykens, E. M., Shah, B., Sagun, J., Beck, T., \& King, B. Y. (2002). Maladaptive behavior and psychiatric disorders in persons with Down's syndrome. Journal of Intellectual Disabilities Research, 46(6), 484-492.

Eisenberg, N., Cameron, E., Tryon, K., \& Dodez, R. (1981). Socialization of prosocial behavior in the preschool classroom. Developmental Psychology, 17(6), 773-782.

Fishler, K., \& Koch, R. (1991). Mental development in Down syndrome mosaicism. American Journal on Mental Retardation, 96(3), 345-351.

Glat, R., \& Kadlec, V. P. S. (1984). A criança e suas deficiências: Métodos e técnicas de atuação psicopedagógica. Rio de Janeiro, RJ: Agir.

Gresham, F. M. (2000). Assessment of social skills in students with emotional and behavioral disorders. Assessment for Effective Intervention, 26(1), 51-58. 
Gresham, F. M. (2009). Análise do comportamento aplicada às habilidades sociais. In Z. A. P. Del Prette \& A. Del Prette (Eds.), Psicologia das habilidades sociais: Diversidade teórica e suas implicações (pp.17-66). Petrópolis, RJ: Vozes.

Hildebrand, F. C. (2000). Dificuldades de aprendizagem: Habilidades sociais presentes nas interações. Dissertação de Mestrado não-publicada, Universidade Federal de São Carlos, SP.

Kaplan, H. I., Sadock, B. J., \& Grebb, J. A. (1997). Retardo mental. In H. I. Kaplan, B. J. Sadock, \& J. A. Grebb, Compêndio de Psiquiatria: Ciências do comportamento e Psiquiatria Clínica (7. ed., pp. 955-969). Porto Alegre, RS: Artes Médicas.

Krebs, D. (1983). Commentary and critique: Sociobiological approaches to prosocial development. In D. L. Bridgeman (Ed.), The nature of prosocial development. London: Academic Press.

Lange, J. L., \& Jakubowski, P. (1976). Responsible assertive behavior. Illinois, MA: Research Press.

Maag, J. W. (2006). Social skills training for students with emotional and behavioral disorders: A review of reviews. Behavioral Disorders, 32(1), 5-17.

Martini, M. L. (2003). Variáveis psicológicas de professores e alunos, ações interativas e desempenho acadêmico. Investigando possiveis relações. Tese de Doutorado não-publicada, Faculdade de Filosofia, Ciências e Letras, Universidade de São Paulo, Ribeirão Preto, SP.

Pereira-Silva, N. L. (2000). Crianças pré-escolares com síndrome de Down e suas interações familiares. Dissertação de Mestrado não-publicada, Universidade de Brasília, DF.

Pereira-Silva, N. L., \& Dessen, M. A. (2002). Síndrome de Down: Etiologia, caracterização e impacto na família. Interação em Psicologia, 6(2), 167-176.

Radke-Yarrow, M., Zahn-Waxler, C., \& Chapman, M. (1983). Children's prosocial dispositions and behavior. In P. H. Mussen (Series Ed.) \& E. Hetherington (Vol. Ed.), Handbook of Child Psychology: Vol. 4. Socialization, personality and social development (pp. 469-546). New York: Wiley.

Rosner, B. A., Hodapp, R. M., Fidler, D. J., Sagun, J. N., \& Dykens, E. M. (2004). Social competence in persons with Prader-Willi, Williams and Down's syndromes. Journal of Applied Research in Intellectual Disabilities, 17(3), 209-217.

Rushton, J. P. (1982). Social learning theory and the development of prosocial behavior. In N. Eisenberg (Ed.), The development of prosocial behavior (pp. 77-105). London: Academic Press.

Schwartzman, J. S. (1999). Generalidades. In J. S. Schwartzman (Ed.), Sindrome de Down (pp. 16-31). São Paulo, SP: Mackenzie.

Skinner, B. F. (2002). Questões recentes na análise comportamental (A. L. Néri, Trad., 3. ed.). Campinas, SP: Papirus. (Original work published 1989)

Skinner, B. F. (2003). Ciência e comportamento humano (J. C. Todorov \& R. Azzi, Trads., 11. ed.). São Paulo, SP: Martins Fontes. (Original work published 1953)

Soresi, S., \& Nota, L. (2000). A social skill training for persons with Down's syndrome. European Psychologist, 5(1), 33-43.

Walker, H. M., \& Severson, H. H. (2002). Developmental prevention of at-risk outcomes for vulnerable antisocial children and youth. In K. L. Lane, F. G. Gresham, \& Tam E. O'Shaughnessy (Eds.), Interventions for children with or at risk for emotional and behavioral disorders (pp. 177-194). Boston: Allyn \& Bacon. 